\title{
Globalization and Identity/Locality Formation: Beyond the "Homo-Hetero" Debate
}

\begin{abstract}
Semir Yesuf*
Abstract

This short article tries to problematize a commonplace discourse in the sociology of globalization, viz., the problem of identity or locality formation. After briefly traversing the two major camps in the field-the "homogenizers"” and the "heterogenizers'"--it finally seeks a way out of this predicament, which it assumes to be virtually untenable. It rather attempts to demonstrate the validity of the insight of those recent scholars who emphasized that "the local" and "the global" are neither strictly distinct nor necessarily contradictory. The term "glocalization" can best stand for such reasoning. This is briefly exemplified by the nature and incidence of one ubiquitous phenomenon in our world: nationalism.
\end{abstract}

\section{Introduction}

Are we melting away into one in this new global era or are we "tracing back" our distinctness every now and then? This set of questions can be said to have roughly caged the otherwise "jargonized" debate on homogenization and heterogenization, respectively. Very roughly put, scholars who represent the homogenizers' camp would argue that we are experiencing an irresistible assimilative wave which blows in accordance with the law of the nature of the flow of power-from the higher altitude to the lower one. In this sense, it is a process of "uniformization" that we are experiencing in the world-all "parochial", "weaker" identities and cultures yielding to and getting incorporated into the cultures/tenets of those powers wielding much influence in the world.

This line of argument would not convince their contenders. The recent developments in our world, the latter counter-cry, tend to give more credibility to the heterogenization perspective. The creation and maintenance of new identities and the resurgence of older ones in various forms (not excluding ethnicity and religiosity) would but render the former view "simplistic" and "outmoded". While, on the one hand, some of these "localized" identities seem to get re-enforced in contradistinction to globalization, others are resurging through it.

These are the debates this article tries to unravel, albeit sketchily. Whereas these debates are partly analyzed, it will be attempted to transcend them. This is done by starting to look at the whole subject of the debate through a different concept, one that takes both "the local" and "the global" as two faces of the same coin.

\footnotetext{
* Lecturer, Department of Political Science and International Relations, Addis Ababa University
} 


\section{Identity}

It may be true that the discovery of the "true" self may "help us to sleep well at night" (Hall, 1991b: 43), but its laborious scientific study is not so promising. The intricacies encompassing the subject identity surely renders its investigation quite sophisticated and lengthy. Even more so, in an unprecedentedly global age, where it hits its record in terms of complexity and delicacy. In this brief theoretical exposition, only a few, but conspicuous points will be treated in that regard. Let's take identity itself initially, as a prelude to our major topic of discussion, namely, globalization and identity.

It has been in the long tradition of the study of identity to argue about its constructionist/instrumentalist, or primordial origin. The assertions in favour of the unproblematical nature and security of particular identities as the basis of claims to some sort of fundamental givenness of identity make up the primordialist paradigm. Taking national identity as an example, proponents argue that historical research shows however dim continuities between, say, modern national cultures and their antecedents, and in patterns of geopolitical regions and relations (Calhoun, 1997:30). One can also see that nationalism derives much of its force from the phenomenological experience of ordinary people that in general their nations/ ethnies have always been there. Many of the cherished elements of national cultures are not created by individuals, i.e., elites. In fact, individuals only become persons in social relationships that are already shaped by culture (Ibid).

However, against such "temptations", it is quite clear, for others, that identity is the outcome of complex series of social processes, and does not arise spontaneously but is learned and re-learned over time (Preston, 1997: 4). We can clearly witness that many aspects of these social worlds are products of human action and subject to potential manipulation (Brass, 1979, 1991). Constructivists do underestimate the power of culture and the force of taken-for-granted identities to get along in the world. It would be rare (just to be safe!) "to find cultures so clearly discrete, non-overlapping and distinct that they automatically become the basis for different social groupings" (Calhoun, 1997:32). Rather, ethnic/national identities are mostly multiple, subject to choice, and dependent on the situation in which they find themselves.

The issue, as Calhoun rightly states, is not just whether cultural commonalities exist, but how they are constructed and reconstructed as they are called into action by leaders and ideologues. Brass's (in Ibid) insight is also remarkable: "The leaders of ethnic movements invariably select from traditional cultures only those aspects that they think will serve to unite the group and that will be useful in promoting the interests of the group as they define them." It is this latter constructionist paradigm which seems to constitute a point of wide agreement in one of the fastest growing bodies of literature in the social sciences (Poppi, 1997: 289).

Implicit in the constructivist's contention is the impermanence of identity. Identity formation involves construction and re-construction throughout the life-course of individuals and groups and through their different faces, roles and circumstances (Melucci quoted in Kennedy, 2001: 2-3). Identity is always in the process of formation. "Though we have always known it a little bit", writes Hall (1991b: 47), "we have always thought about ourselves as getting more like ourselves everyday." The search for the "self" pauses at various ends but never stops permanently. 


\section{Globalization}

From the outset, let me take sides on some aspects of the contentious concept of globalization (particularly, the sociology of globalization). We now know that globalization as a process towards a global (economic, cultural or political) community has come into question by some writers (such as Hirst and Thompson, 1996)--and they are partly right. They have indeed contributed a great deal to disclosing the real weaknesses of the "hyperglobalist position" (which tends to exaggerate the making of a "global community") (Held, 2002:2). Some of these writers (who take issue in "hyperglobalism") use the term "globalization" to examine how nation- states fit into patterns of history that are potentially global in reach and into a macro-sociological theory that aims to be all-encompassing (Shroeder,1999:71).

On the other hand, however--and herein lies their misjudgment--the writers have also tended "to throw out the baby with the water" (Held: Ibid) in that they have not just corrected the "hyper", but also lost touch with what has changed. It seems more convincing, then, to also subscribe to the idea that globalization is a "matter of increasing long-distance inter-connectedness, at least across national boundaries, preferably between continents as well” (Hannerz quoted in Shuerkens, 2003:212). It may not seem wise to exclusively claim either of the extreme views. In short, globalization, seen both as an actual process and as an expression of a pattern of history that is potentially global may be useful depending on the research topic we focus on.

We had, finally, better remain in sympathy with the historical definition of globalization (Dutceac, 2004) that places the events currently observed in the longue durée. What we experience today is not discontinuously new; it has been going on for decades and centuries, only in different forms and varying degrees of intensity. Accordingly, one would not also have any difficulty in accepting the unique features of the currently prevailing condition of globalization. Most scholars associate the end of the Cold War with the period of high impetus of globalization (Dutceac, 2004: 21), although some others place it around the early 1980s (Hirst and Thompson, 1996).

\section{Globalization and Identity: The "Homo-Hetero" Debate}

The general thrust of the discussion here will be in accordance with Featherstone's and Lash's (1995) notion that the rise of the globalization problematique represents the spatialization of social theory. While this may seem to resonate with the claims of postmodernity--privileging the spatial over the temporal--the latter never escaped the opportunity of being viewed from a temporal vantage point. It can well be examined as a paradigm developed in the pre-modern, modern and post-modern chain of socio-political theoretical framework. In this context, the concept of globalization represents an important shift in transmuting this temporality into a spatial frame of analysis (Ibid: 1 ).

Perhaps the debate which becomes most relevant to this framework--in connection to "identity"--is the one which encases the homogenization- heterogenization problematique. One can safely categorize, under the advocates of the former stance, those perspectives rooted in the well -known modernization paradigm. This paradigm is, risking an abrupt summary, known to have been a historical legacy that was based on the fundamental 
assumption that the evolution of modern industrial societies signaled the demise of certain forms of solidarity and the rise of new forms, predicated in no small part on the idea that individuals would be increasingly free from the ascribed particularistic identities characteristic of traditional or pre-modern societies and would enter a world based on individual achievement and universal values (Kivisto, 2002:20). Accordingly, the modernization of traditional societies is constituted by a bundle of core processes such as nation-state formation, social differentiation, individualization, capitalist development, political modernization and secularization (Spohn, 2003: 267). Modernity's straight path is seen to be the fate--a "graceful" fate!--of all societies of our world.

Some writers have extended this approach further to underpin their discourse of globalization theory. Here, globalization (and globality) is taken to be a consequence of modernity (See, for example, Giddens, 1990). It is seen as a multidimensional generalization of the Western model of modernity and, with it, the dissemination of the nation-state, capitalist production and the homogenization of national cultures. For some scholars (for example, Mann, as paraphrased by Spohn, 267-69), the spread of ethnic and religious nationalism is seen as a part of the conflicting process of nation-state formation with a secular culture in a multicultural setting. For others (such as Poppi, 1996), it is explained (or explained away?) as "the unfinished agenda" of modernization. But for all modernist "homogenizers" one thing is clear: they would at least implicitly invoke a scenario of convergent development; and globalization does serve as a spectacular engine to this end.

It is now quite needless to say that modernization's linear path has been discredited from different angles, and need not be treated here any more ${ }^{1}$. Its offshoot, "the globalization-as-homogenization” perspective has also met with sharp counter-arguments. In contrast to the former's simplification of reality, we have been witnessing since recent times a steep rise, not decline, of "parochial” life-worlds. Ethnic and religious nationalisms, to mention but a few, have riven across almost all parts of our world today. Explanations in defiance of the homogenizers' paradigm do vary: a general defensive reaction of nonWestern societies to the intensifying forces of Western-dominated globalization ${ }^{2}$; the incessant quest for a permanent "home" within a rapidly moving ocean of existence and its

${ }^{1}$ One can refer to the bulky literature produced by, for instance, dependency and world-system theorists.

${ }^{2}$ This view is represented primarily by post-modernists and "Wallerstenians" (from Immanuel Wallerstein). While the claims of post-modernists and the counter-claims of their critiques abound in scholarly works (see, for instance, Craig Calhoun's Critical Social Theory), for a brief critical treatment of Wallerstein's view, one can refer, among many others, Leslie Sklair's, Globalization, pp.40-42, and Albert Bergesen's, "Turning World-Systems Theory on its Head", pp.67-83. My special problem with these views is not that reactive moves never occur in inter-group interactions but that, a) these alone won't explain fully all forms of identity constructions, and b) behind or beside every reactive move there is also an interpenetrative and complimentary companionship in the making. 
corollaries $^{3}$; and a manifestation of the multiple modernization processes of different societies in their own path of development ${ }^{4}$. All these perspectives, however much they differ in their conceptualizations of identity construction, do share the view that the world we are currently encountering can indeed be characterized by increasing, mind- boggling complexity.

Heterogenizers would tend to dispute(say, Said, 1978) that a system existed; disclaim (say, Hall, 1991a, 1991b) the distinction of "universal" and "particular", considering the "global as the self-presentation of the dominant particular" (Hall, 1991b: 67). What we have is just the (re-) production of different particulars. For such incontestable heterogenizers as Jan Pieterse (1995), globalization is seen as hybridization, in which forms become separated from existing practices and recombine with new form in new practices. It is not a condition for modernization, but instead an historical epoch, co-existing with postmodernity. Modernity, for its part, is contemporaneous with an earlier period of the hegemony of the nation-state. After having disowned both functionalist modernization theory and Marxist dependency theory for their modernist tendency of the nation-state period, Pieterse concludes that true globalization theory is the post-modern analysis of hybridity (see the summary by Featherstone, et. al, 1995: 5).

It would indeed be as difficult to yield to a wholesale acceptance of all these heterogenist assertions as to bend to a wholesale rejection of all. We need not miss to realize some tendencies of maintaining traditional life-worlds as reactive moves against "colonizing" waves of socio-cultural domination. Similarly, and more convincingly, contemporary, say, ethnic communities and identities in many regions of the world have not faded and will not fade away with the inevitable advance of global modernity, but rather represent critical aspects of that particular region's experiences of modernity itself ${ }^{5}$. This "multiple modernity" paradigm would particularly emphasize that such growth in suband supra- national nationalism, especially in the non-Western world, can be attributed to the multiple forms of modernity, modernization and democratization in reaction to the former world-wide imposition of state secularism, western or eastern type (Berman, et. al., 2003; Eisenstadt, 2000; Spohn, 2003) .

${ }^{3}$ See, for instance, Hall, 1991a, 1991b. I am somewhat skeptical of the tendency to consider the recent era of globalization as being radically unique in compelling us to live in a condition of homelessness or rootlessness. (For elaborations, see Robertson, 1995:35).

${ }^{4}$ This "multiple modernity" approach is best represented by Eisensdadt, 2000 and Spohn, 2003. For criticisms, see Schmidt, 2004. I regard this approach highly useful for its analytic capacity to study the development of non-Western societies. However, I personally would a) sense an aroma of teleology in that it carves out inevitable, linear continuities in the processes of the transformations of socio-cultural traditions of societies, and b) tend to disagree with its attribution of the rise of ethno-nationalisms in non-Western societies always to the imposition of state secularism.

${ }^{5}$ This view, very similar to, if not exactly alike, the "multiple modernity" approach referred to above, is well-presented in Berman, Bruce, et. al, Ethnicity and Democracy in Africa. 
Contrariwise, we would find these assumptions taking us not too far. For instance, the representation of different identities (either those to be "creolized"6 or those to settle as "distinct" identities) as contradictory and confrontational (for instance Giddens, 1990; Hall, 1991a) does not necessarily correspond to reality. In a similar vein, heterogenization should not be taken as the only typical feature of the globalization process /global system, any more than its apparent opposite, homogenization. In our world today, similar processes of localization are taking place universally, and universalizing processes are being played locally, reflecting a situation where homogenization and heterogenization can never be seen as mutually exclusive expressions of reality but as the two faces of the same movement.

It is, then, I think, clear that the crudity these bifurcations create in our understanding of the globalization-identity/locality dynamics should be redressed. This can take place only when we seek for another concept that can transcend this aporia. We will discuss the features of this concept and its ability to grasp the intricate process of identity/locality construction in the next section.

\section{Transcending the Global -Local Counterpoise}

The concept which is supposed, in this article, to ameliorate the problems indicated so far is represented by the term "glocalization" (globalization + localization), a term frequently associated with sociologist Roland Robertson (1995). This concept is chosen to couch our discussions to come not because it appeared flawless to the author. In fact, some critiques, a few of which will be mentioned later in the article, can be launched against it. Rather, its relatively exquisite congruity with the reality of the issues in question in general would make it appear to be more dependable than other relevant concepts in the field. In the following lines, I will try to reiterate selectively the meaning and implications of the term as expounded by Robertson himself, along with some reflections of my own.

Robertson (1995) makes a spring board of those concerns which we have already glimpsed over in the earlier lines. He specifically finds unpalatable the attempts of some social theorists who, while analyzing the very idea of globalization, counterpoise the "local" with the "global". This counterpoise is stretched over two, but very much interwoven, fronts: on the one hand, the "global" is analytically considered in distinction to the "local", as if the former has to be studied and lived in its own terms just as the latter. This is revealed in the expressions (common in numerous texts and discourses), among others, "the global and the local", "the global and the tribal", "the international and the national" and "the universal and the particular".

On the other hand, in close connection with the above evaluation, the "global" is presented as being at loggerheads with the "local" and vice versa. This "tensing" way of drawing the global-local dynamics (and, globalization as the opposite of localization)

6 “'Creolization' appears in writings on globalization and post-modernism as a synonym of hybridity and syncretism to depict the mixtures occurring among societies in an age of migration and telecommunication” (Stewart, 2002). 
would mean that if ever the two meet, then it is a clashing encounter that we come across. This encounter is well-manifested in such discourses as "the global versus the local", "the international versus the national", "the universal versus the particular" and so on. For some, these alleged oppositions are simply puzzles; for others, the second of the items in tension in each pair is a reaction against the first, while, still for others, they are merely contradictions. It is exactly these "abstractions" which, for Robertson, expose the "lagging behind real life" of academic disciplines, which induced him to introduce the concept of "glocalization" "firmly"--as he says--into social theory.

Such forked imaginations of the global and the local (and by extension, homogenization and heterogenization), in Robertson's view, neglect two things. First, they neglect the extent to which what is called "local" is in large degree constructed on a transor supra- local basis. In other words, much of the promotion of locality is in fact done from above or outside. "Even in cases where there is apparently no concrete recipe at work", he (Ibid: 26) writes, "there is still... a translocal factor at work". He maintains that the contemporary assertion of ethnicity and nationality is made within the global terms of identity and particularity.

The second point is concerned with the problem Robertson identifies in the little attempt to connect the discussion of time-and-space to the "thorny" issue of universalismand-particularism. In spite of the few serious efforts (by the theme of post-modernity) to resist the tendency of granting much concern to "universal time" and that of the downplaying of the attention "particularistic space" deserves, universalism has been persistently posed counter to particularism. Besides, the emphasis on space is frequently expressed as a diminution of temporal considerations (Ibid).

Based on these assumptions, then, the question worth- asking for Robertson is not whether the universal and the particular can be interrelated but how they in fact do so. In an attempt to respond to that question, he goes on to attend to the subject as to what is actually going on. Hannerz (1990), among others, helps him in some respects. He remarks that for locals diversity "happens to be the principle which allows all locals to stick to their respective cultures." At the same time, cosmopolitans largely depend on "other people" carving out special "niches" for their cultures. Thus, "there can be no cosmopolitans without locals" (Hannerz, 1990: 250).

In the same vein, Robertson (Ibid: 30) maintains that globalization has involved the reconstruction, in a sense, the production, of "home", "community" and "locality". To that extent, he continues, the local is not best seen as a counterpoint to the global. Indeed it can be regarded, subject to some qualifications, as an aspect of globalization. Consequently, for a "glocalizer" like Robertson, Barber's (mentioned in Ibid, 33-34) strict (contra) distinction between "tribalism" and "globalism", or "McWorld" homogenization versus a "Jihad world" heterogenization is simply shallow. This way of defining the global suggests that the global lies beyond all localities, as having systemic properties over and beyond the attributes of units within a global system. It defines the global as if the global excludes the local.

Robertson tries to illustrate his thesis with examples. His example regarding the nature of the nation-state may be worth-noting. He emphasizes that nationally organized societies, 
and the "local" aspirations for establishing yet more nationally organized societies, "are not simply units":

within a global context. Both their existence, and particularly the form of their existence, is largely the result of extra-societal--more generally, extra-local--processes and actions... Much of the apparatus of contemporary nations, of the national-state organization of societies, including the form of their particularities--the construction of their unique identities--is very similar across the entire world, in spite of much variation in levels of development. (Ibid: 34)

Nation-states, in other words, are representative examples of "glocal" entities, coming into existence in a typically "glocal" way. This is why the same scholar concludes (Ibid: 34) that "they are the most tangible of contemporary sites of the interpenetration of particularism and universalism. We will come to this point later in this paper.

Robertson is therefore persuaded to recommend the substitution of the term "globalization"--in whose employment he perceives major weaknesses--by the concept of "glocalization". In doing so, he believes, one can transcend the tendency to cast the idea of globalization as inevitably in tension with the idea of localization (also resolve the homohetero distinction). Instead, he draws a circular cause-and-effect spiral where globalization has involved the creation and the incorporation of locality, processes which themselves largely shape, in turn, the globalization of the world as a whole.

At any rate, Robertson is never alone in many of what he says. With minor degrees of divergence in terms of depth and focus of emphasis, other scholars have also tried to read the "global"- "local" dynamics through somewhat similar prism[cf. Appadurai, 1996; Shuerkens, 2003; Kivisto, 2002; Luke, 1992; Nedpogaeo, 2001, among many others). I chose to consider his position in some detail because it is succinctly and explicitly stated. [Let's not also forget that he is, in addition, credited with introducing the term "globalization" into sociology (Sklair, 2001)].

But I am of the opinion that few points need further remarks, since I am not fully content that Robertson has given them the emphasis they deserve. The first is the issue of power. This should be stressed in two areas. For one thing, the free use of the term "glocalization" may, I think, sometimes, obscure behind it the nature of the power balance lingering among the identities in question. Here, I would like to admit that any maker (in the sense of "ingredient") of a "glocal" reality may not be skimmed off from its co-maker. Rather, the interaction may evolve into another reality, where it won't be possible to distinguish between the "real" identity from that which has "evolved". But still, where a blending of formerly distinct cultures occurs there may be a possibility to contemplate some sort of power relationship between the here-to-fore distinct entities. My concern is just to note the significance of taking into account the "politics of globalization" which includes, but is not only limited to, John Streets' (1997) conception of the term (in which case is composed of institutional practices, policy process and ideology).

Similarly, it is worth-noting that not all identities/cultures can go "global" or undergo a "glocal" construction process. Globalization, as indicated by Poppi (1997:297), "is 
responsible for selectively sieving which markers of difference can be deployed in the process of constructing the international division of ethnic and cultural labour". To his credit, Robertson, if at times neglects, but is not oblivious of this fact; he has it that "flying globally" depends on issues of power (Robertson, 1995: 39). Unfortunately, he once again relapses to his ideal of "freedom", when he suggests that the latter is manifested particularly in the social construction of identity by the appropriation of cultural traditions. My response is once again Poppi’s. In his (Poppi, 1997: 297) own words, "not all cultural traits can sing in the multicultural chorus, only some." Some others are forgotten, still others repressed. The question of power steps in once again.

Let's, finally, return to the homo-hetero debate. We have seen that these simultaneous trends are, in the final analysis and when seen in a wider scale, complementary and interpenetrative. My intention here is just to underline the italicized phrase/clause. This is because, as acknowledged by Robertson (1995: 40) himself, the two trends certainly can and do collide in concrete situations. In any case, my conviction is that we should develop a holistic insight of the situation we study in order to arrive at the validity of our former contentions. Put otherwise, at a specific juncture, we may feel we have a collision between the two forces, but no sooner will we go on forging a comprehensive outlook towards the matter than we discover another (other) junction(s) where the "homo" and the "hetero" ( or the global and the local) go interlaced in harmony.

At this instance, one may find Jan Pieterse's (1992: 42) perception of the globalization process in plural terms helpful. (He speaks of globalizations.) He conceives the plurality of globalizing either in terms of its multidimensionality as a process, in terms of its multiple modes and agents and dynamics or impulses, or still by differentiating between globalization as policy and project (see Ibid: 46). We can find this useful-- useful to vindicate our "glocal" analytic project.

\section{Nationalism: A Paradigm}

This "global institutionalization of the life-world" and "the localization of globality" (Robertson, 1990:19) can be well-demonstrated when we examine the issue of nationalism. Voluminous literature has been written on the relationship between nationalism and globalization. My intention in this section is confined to just briefly recapitulate some of the arguments raised regarding the issues at hand by way of illustrating the viability of the concept, glocalization.

There was a time when nationalism as an ideology and movement was declared obsolescent in some corners of the academic world. Considered as a "thing of the past, a cause of wars in Europe up to 1945, a relic of colonialism in the Third World, an irrational, if necessary, feature of international relations”(Halliday, 2001:441), it was almost flatly neglected in most books dealing with international relations. With the harmonization of relations between/among states and the independence of former colonial countries, and the resulting efforts by states to conduct international relations with one another through international governmental organizations of all sorts, nationalism, so it was assumed, would go on losing its former significance and attractiveness (Ibid). 
Some other aspects of the globalization process were supposed to play the same role, too. With more and more across-the-board interactions and transnational dealings, localized lives and thoughts, not excluding nationalistic ones, would finally face the inevitable fate of extinction. Hence, so went the argument, globalization stands in sharp contradiction with nationalism, and given the irresistible force mustered by the former, the latter is only waiting for its final death-blow.

The post-Cold War era has attested to the datedness of this very confidence, rather, not that of nationalism. State nationalism, sub-sate nationalism, ethno-nationalism and transnationalism have stood, at least until this day, the test of time in different parts of the world, developing and developed. The steep rise in nationalist politics has led, since recent times, to the re-questioning of the relationship between globalization and nationalism.

On first sight, nationalism seems to have resurged as a reaction to globalization. This is so when we look at, for instance, nationalist movements in the Third World which appeared/developed out of hostility to what was seen as a Westernization or imperialist move. But there is much more to the globalization-nationalism nexus than the above shallow observation. The two phenomena, according to various recent studies, have predominantly gone hand in hand, mostly intermingled in a sort of causal relationship.

We should remember, first of all, that, historically speaking, a unique emphasis on the autonomy of the nation-state, at least in Europe, coincided with and partly caused by the pronounced internationalization of the world (Calhoun: 2001). In this, as Calhoun stresses (2001: 20), may lie some lesson for the present era when

the acceleration of global processes of capital accumulation, the rapid global transfer of technology, the almost instantaneous spread of cultural products, and huge waves of migration lead many to imagine that the nation-state is likely to vanish quickly into the shadows of history.

Nationalism, taken as a doctrine which invokes the distinct culture and history of peoples, spread across the world over the past couple of centuries as part of an international process: "as a result of global changes, old forms of solidarity and loyalty have been broken down, a new idea has been promoted and diffused"(Halliday, 2001:443). This was aided by such international transformations like, the increasing integration of the world market, the establishment of European colonial empires, the world wars and so on (Ibid). A doctrine, then, which espouses difference and uniqueness, spread, to a large degree, ironically, through a process which aspires to embrace the world as a single globe.

Current conditions, too, would but reveal the same dynamics. Indeed, in the "network society", to borrow Castell's (1996) depiction of the electronically globalized world, it would be simplistic to predict the end of nationalism. In such a world, the maintenance of ethnic/national identity will become less dependent upon either a territorial base or formal organizations. It will be possible for national/ethnic links to be sustained with others of similar language and cultural background throughout the world (Richmond, 1994). Interpersonal/group networks may be maintained through videophones and other telecommunication links and through mass communication networks as well, over flying the boundaries of nation-states and penetrating any location throughout the world (Ibid). 
These linkages would no doubt bolster national solidarities in an otherwise spatially fragmented plane.

The dynamics of the spread of nationalism can be partly captured using Appadurai's five dimensions of global cultural flows. There are, firstly, ethnoscapes produced by flows of people: tourists, immigrants, refugees, exiles and guest workers. Then come technoscapes, the machinery and plant flows produced by multinational and national corporations and government agencies. Thirdly, we have finanscapes, produced by the rapid flows of money in the currency markets and stock exchanges. Mediascapes, fourthly, are the repertoires of images and information which are produced and distributed by newspapers, magazines, television and film. Ideoscapes, finally, stand for the flows of images which are associated with state or counter-state movement ideologies (associated with the Enlightenment of the West) which include images of democracy, freedom, welfare, right etc..(Appadurai, 1990; Featherstone, 1990). While these concepts are obviously very important and relevant to our issue at hand, this, however, is not the place to show in some detail how each one of these dimensions operates in relation to nationalism.

By way of demonstration, let's here mention that it is in these very ways that immigrants retain an active interest in, inter alia, the politics of their country of origin. Their participation in homeland politics is very "national”. "In fact," observes Kymlicka (2003:925), "diasporas are often more nationalist than their co-nationals in the homeland". "It is", he (Ibid) continues:

precisely as members of the nation, born and raised in the homeland, that they assert the right to participate in homeland politics, and work to defend its national sovereignty. There is nothing "post-national" about the way diasporas participate in homeland politics--it is nationalist politics in every recognizable sense.

Nationalism-permeated, thus, as our world is, we cannot deny that the forms of nationalism and the nation (and the nation-state) are unstatic and changing. One of the many consequences of the process of globalization, as O’Byrne (2001:139) states, has been the separation of nation and state, and thus the end of the hyphen between the two. The reason behind this divergence between the nation and the state in the global here and now goes to the fact that they are developing distinct relations to territoriality and territory (Berking, 2003). While the state remains obstinately bound up with its original territoriality and sovereignty, the nation has become remarkably (ultra?) flexible in its handling of the nation-territory alignment.

States, no longer exclusively able to guarantee the territorial organization of markets, life-worlds, identities and histories, are forced to compete with a bewildering diversity of providers of identity options (Ibid). Consequently, whereas it is premature to speak of the end of the modern state, one cannot miss to consider a significant reconfiguration process of the relation between state, territoriality, sovereignty and identity. Arguably, therefore, nations and nationalisms are constantly de-territorialized and re-territorialized flexibly on 
a transnational plane, leaving the state porous to competing "market for loyalties" (Appadurai, cited in Berking, 2003: 254).

Nationalisms, therefore, are upheld in this new global era as they were half a century ago, only in different forms. Just as their formation was closely linked to global lifeworlds, they have remained so, perhaps more so, throughout, and we are likely to witness the same thing in the years ahead. In the end, nationalism has been proven not to be an "alternative to globalization, but an intrinsic part of it" (Halliday, 2001: 454). Glocalization ever seems to hold true.

\section{Conclusion}

In this brief paper, we have tried to complicate the otherwise shallow relationship between identity/locality formation and development, on the one hand, and globalization, on the other. In contrast to both the arguments (the "homo-hetero" debate) which read the relation in a rather black-or-white way, the connection should be seen in a more sophisticated way where homogenization and heterogenization, and globalization and localization as well, happen to interpenetrate one another and co-exist at a particular place and time. A good example for this dynamics can be the case of the globalization-nationalism nexus which continuously refuse to reflect the condition of either homogenization only or just heterogenization. While, on the one hand, difference and separateness of people is all the more pronounced everywhere, this phenomenon is spread, sustained, and is mostly seen to have acquired similar overall logic and feature all over the world, because of globalization. This is what makes nationalism a glocal—both global and local at the same time-project and occurrence par excellence.

\section{References}

Appadurai, A. 1990. "Disjuncture and Difference in the Global Cultural Economy", in M. Featherstone (ed.), Global Culture: Nationalism, Globalization and Modernity. London: Sage Publication.

1996. Modernity at Large: Cultural Dimensions of Globalization. Minneapolis, MN: University of Minnesota Press.

Bergesen, Albert. 1990. "Turning World-Systems Theory on its Head”, in M. Featherstone (ed.), Global Culture: Nationalism, Globalization and Modernity. London: Sage Publication.

Berking, Helmuth. 2003. “"Ethnicity is Everywhere”: On Globalization and the Transformation of Cultural identity”, in U. Schuerkens (ed.), Current Sociology. Vol. 51, No. 3/4, pp. 248-64.

Berman, Bruce, et. al. 2004. "Introduction: Ethnicity and the Politics of Democratic Nation-building in Africa”, in B. Berman, et. al. (eds.) Ethnicity and Democracy in Africa. Oxford: James Currey Ltd.

Brass, Paul. 1979. "Elite Competition and Nation-formation”, in J. Hutchinson and A. Smith (eds.) (1994), Nationalism. Oxford: Oxford University Press. 
1991. "Ethnic Groups and Ethnic Identity Formation”, in J. Hutchison and A. Smith (eds.) 1996. Ethnicity. Oxford: Oxford University Press.

Calhoun, Craig. 1997. Nationalism. Minneapolis: University of Minnesota Press.

Dutceac, Anamaria. 2004. "Globalization and Ethnic Conflict: Beyond the LiberalNationalist Distinction”, in The Global Review of Ethno- Politics. Vol.3, No.2, pp. 2039.

Eisenstadt, S.N. 1998. "Multiple Modernities”, in Truman Institute Reprints (n.d.). Jerusalem: The Hebrew University.

2000. "Multiple Modernities”, in Truman Institute Reprints (n.d). Jerusalem: The Hebrew University.

Featherstone, Mike and S. Lash. 1995. "Globalization, Modernity and the Spatialization of Social Theory: An Introduction”, in M. Featherstone, et. al. (eds.), Global Modernities. London: Sage Publications.

Friedman, J. 1994. Cultural Identity and Global Process. London: Sage.

Geschiere, Peter and B. Meyer. 1998. "Globalization and Identity: Dialectics of Flow and Closure: Introduction”, in P. Geschiere and B. Meyer (eds.), Globalization and Identity: Dialectics of Flow and Closure. London: Routledge.

Giddens, Anthony. 1990. The Consequences of Modernity. Cambridge: Polity Press.

Hall, S. 1991a. "The Local and the Global: Globalization and Ethnicity”, in A.D. King (ed.), Culture, Globalization and the World-system: Contemporary Conditions for the Representation of Identity. Hampshire: MacMillan Press Ltd.

1991b. "Old and New Identities, Old and New Ethnicities”, in A.D. King (ed.), Culture, Globalization and the World-system: Contemporary Conditions for the Representation of Identity. Hampshire: MacMillan Press Ltd.

Hannerz, Ulf. 1990. "Cosmopolitans and Locals in World Culture”, in M. Featherstone (ed.), Global Culture: Nationalism, Globalization and Modernity. London: Sage Publication.

Held, David. 2000. "Globalization: the Argument of Our Time”, at: http://www.opendemocracy.net/debates/article.jsp?id=6\&debateId=28\&articleId=637.

Hirst, Paul and G. Thompson. 1996. Globalization in Question. Cambridge: Polity Press.

Kennedy, Paul. 2001. "Introduction: Globalization and the Crisis of Identities", in P. Kennedy and C.J. Danks (eds.), Globalization and National Identities: Crisis or Opportunity. New York: Palgrave.

Kivisto, Peter. 2002. Multiculturalism in a Global Society. Oxford: Blackwell Publishers Ltd.

Luke, T.W. 1995. "New World Order or Neo-World Orders: Power, Politics and Ideology in Informationalizing Glocalities”, in M. Featherston, et. al. (eds.), Global Modernities. London: Sage Publication.

Nedpogaeo, Asawin. 2001. "Global Culture in the Thai Media: The Occidental 'Other' in TV Advertisements”, in P. Kennedy and C.J. Danks (eds.), Globalization and National Identities: Crisis or Opportunity. New York: Palgrave.

Pieterse, J.N. 1995. "Globalization as Hybridization”, in M. Featherston, et. al. (eds.), Global Modernities. London: Sage Publications. 
Poppi, Cesare. 1997. "Wider Horizons with Larger Details: Subjectivity, Ethnicity and Globalization", in A. Scott (ed.), The Limits of Globalization: Cases and Arguments. London: Routledge.

Preston, P. W. 1997. Political/Cultural Identity: Citizens and Nations in a Global Era. London: Sage Publications.

Robertson, Roland. 1995. "Glocalization: Time-Space and Homogeneity-Heterogeneity", in M. Featherstone, et. al. (eds.), Global Modernities. London: Sage Publications.

Said, Edward. 1978. Orientalism. New York: Pantheon Books.

Schmidt, V.H. 2006. “Multiple Modernities or Varieties of Modernity?”, in Current Sociology. Vol.54, No.1, pp.77-97.

Schuerkens, Ulrike. 2003a. "Social Transformation between Global Forces and Local LifeWorlds: Introduction”, in U. Schuerkens (ed.), Current Sociology. Vol.51, No.3/4, pp.195-208.

2003b. "The Sociological and Anthropological Study of Globalization and Localization”, in U. Schuerkens (ed.), Current Sociology. Vol.51, No.3/4, pp.209-222.

Shroeder, Ralph. 1999. "Rethinking Nationalism in the Context of Globalization", in K.J. Brehony and N. Rasool (eds.), Nationalisms: Old and New. London MacMillan Press Ltd.

Sklair, Leslie. 2002. Globalization: Capitalism and its Alternatives. Oxford: Oxford University Press.

Spencer, Philip and H. Wollman. 1999. "Blood and Sacrifice: Politics versus Culture in the Construction of Nationalism”, in K.J. Brehony and N. Rassool (eds.), Nationalisms: Old and New. London: MacMillan Press Ltd.

Spohn,Willfried. 2003. "Multiple Modernity, Nationalism and Religion: A Global Perspective”, in U. Schuerkens (ed.), Current Sociology. Vol.51, No. 3/4, pp.265-286.

Stewart, Charles. 2002. "Creolization and Diaspora: Historical, Ethnographic and Theoretical Approaches”, at: http://www.transcomm.ox.ac.uk/events/Creolization.htm.

Street, John. 1997. “'Across the Universe': The Limits of Global Popular Culture”, in A. Scott (ed.), The Limits of Globalization: Cases and Arguments. London: Routledge. 